\title{
Fabrication, Characterization and Mechanical Stability Performance Test of Cellulose Acetate Membrane Filled with Lampung Natural Zeolite (Ca/LNZ)
}

\author{
D A Iryani ${ }^{1,4, *}$, A W Cindradewi ${ }^{1}$, S B Ginting ${ }^{1}$, E Ernawati ${ }^{2}$, U Hasanudin ${ }^{3,4}$ \\ ${ }^{1}$ Department of Chemical Engineering, Universitas Lampung, Jl. S. Brodjonegoro No. 1, Bandar Lampung, Indonesia \\ ${ }^{2}$ Departement of Chemistry, Mathematics and Science Faculty, University of Padjajaran, Bandung, Indonesia \\ ${ }^{3}$ Departement of Agro-industrial Technology, Universitas Lampung, Jl. S. Brodjonegoro No. 1, Bandar Lampung, \\ Indonesia \\ ${ }^{4}$ Research and Development Center for Tropical Biomass, Universitas Lampung, Jl. S. Brodjonegoro No. 1, Bandar \\ Lampung, Indonesia \\ *Corresponding author. Email: dewi.agustina@eng.unila.ac.id
}

\begin{abstract}
The hybrid membranes for pervaporation of ethanol-water mixture were prepared by filled Lampung natural zeolite (LNZ) into cellulose acetate (CA) casting solution in the varied ratio of CA:LNZ (30:0, 30:5, 30:10, 30: 20, 20:20 and 40:10) wt $\%$. The effect of zeolite addition on the resulting membranes were characterized by using Fourier transform infrared spectroscopy (FTIR), thermogravimetric analysis (TGA) and scanning electron microscope (SEM) and X-raydiffraction (XRD) analysis, which aims to observe the crystallinity, morphology, and thermal and mechanical stability of hybrid membrane. The results show that the interaction between the LNZ particles and CA were making the thermal stability, crystallinity, and hydrophilicity of the hybrid membrane improved compared with pure CA membrane.
\end{abstract}

Keywords: Celullose acetate membrane, Hybrid membrane, Pervaporation membrane, Lampung natural zeolite.

\section{INTRODUCTION}

The technological developments of membrane separation process in the industrial world are already widespread and widely applied in industries including chemicals [1], bio-ethanol [2], water purification [3,4], metals [5], food [6], gas purification [7,8] and so on. Separation process using membrane-based process has several advantages compared to other conventional separation methods such as distillation and extraction because it is more simple, environmental friendly and low energy requirement $[9,8,10]$.

Currently, the evaporation membrane application for purification of bioethanol has attracted considerable attention since it has a high efficiency, the simplicity of separation, and a low operation cost [2,11,12]. Pervaporation is one of the purification method by using a membrane-like material for separation of a mixture of liquids by partial vaporization. Pervaporation has several advantages compared with the conventional distillation, since it has the ability to separate the azeotropic mixture, no additives required and relatively low energy consume [11]. Membrane pervaporation technique is used to separate a liquid mixture by partly vaporizing it through a nonporous permselective membrane [12].

Two type of membrane such as organophilic membranes can be used for recovery of bioethanol from a fermentation broth, while hydrophilic membranes usually apply to dehydration of ethanol near to azeotrope point in a hybrid distillation-pervaporation process [2]. Hydrophilic membranes are often used on pervaporation of ethanol-water. Hydrophilic membranes consist of three types, i.e: (1) polymeric membranes which are based on organic polymer chains that are cross-linked together, (2) inorganic membranes, fabricated from ceramics or zeolites, and (3) composite membranes that are based on an organic polymeric membrane but have inorganic particles dispersed throughout the polymeric structure, these are commonly termed mixed matrix membranes [11].

Generally, polymeric membranes are the most commonly used in the membrane separation processes. Among of polymeric material type, cellulose acetate (CA) is widely applied to separate substances in liquid and gas phase (CA), due to its advantages characteristics 
such as easy to produce and derived from natural renewable substances, low price, moderate chlorine resistance, good toughness, high biocompatibility and hydrophilicity $[1,4,8,9,10,13]$. However, CA membrane is not suitable for more aggressive cleaning as it has easily oxidized and low chemical resistance and mechanical strength $[1,9,13]$. Thus, a special treatment is required to improve CA performance by adding nonporous inorganic additives such as alumina, silica, and titania as fillers into CA membrane in order to correct its deficiency properties in accordance with the type of membrane that will be in production $[1,8,9,17]$. The presence of inorganic material able to improve mechanical stability, increasing fouling resistance ability, surface porosity, permeability properties and membrane selectivity in separation processes $[4,14,15]$.

Various types of porous inorganic fillers such as zeolites and carbon molecular sieves also have been used in mixed matrix membranes. Several researchers have been investigated the effect of the addition of a porous inorganic filler such as zeolite and carbon molecular sieves into organic polymer [16-18]. Ling et al. (2008) had studied the pervaporation separation of ethanol-water mixture using PVA zeolite-clay membranes to investigate the effect of ethanol feed concentration (10\%, $30 \%, 50 \%, 70 \%$ dan $90 \%)$ and operation temperature (30, $40,50,60$, and $70{ }^{\circ} \mathrm{C}$ ). The investigation shows that incorporation of zeolite into matrix membrane able to increase the selectivity in accordance with the increases of ethanol concentration and operating temperature. However, on the contrary, the absorption (flux) of the membrane is decrease. The other research conducted by Ma et al. (2009), prepared the HZSM5-filled cellulose acetate (CA) membranes by incorporating the HZSM5 into CA for pervaporation separation of methanol/methyl tertiary butyl ether (MTBE) mixtures. Their study found that the permeation flux increased while the separation factor decreased with increasing the amount of methanol in the feed, when operating temperature of pervaporation increase from $298 \mathrm{~K}$ to $323 \mathrm{~K}$.

A search of the literature reveals that zeolite synthetic are widely used as a filler of polymeric membranes in the view of their better performances. While, to our knowledge, only one study [19] reported the natural zeolite used as a filler of polymeric membrane. The natural zeolites clinoptilolite has been used mainly as the silica source. The use of natural zeolite as an polymeric membrane filler has gained great interest due to its large deposits and it has some promising benefits since they are lower in cost.
In this work, natural zeolites clinoptilolite from Lampung Province (LNZ), Indonesia, was used as a filler to modified CA membrane. The chemical composition of the natural zeolite used in this experiment mainly consisted of (in wt \%) $78.17 \mathrm{SiO}_{2}: 16.80 \mathrm{Al}_{2} \mathrm{O}_{3}: 1.42 \mathrm{~K}_{2} \mathrm{O}$ $1.36 \mathrm{CaO}: 0.82 \mathrm{MgO}: 0.87 \mathrm{Fe}_{2} \mathrm{O}_{3}$. The ratio of natural zeolite addition was varied from 5 to $30 \mathrm{wt} \%$ into the casting solution based on $\mathrm{Ca}$ amount. The objective of this research work is to develop high-performance of modified membranes and investigate the effect of zeolite addition on the morphological, thermal and mechanical properties of the developed membranes by using the instrument of Fourier transform-infrared, scanning electron microscope, thermogravimetric analysis, universal testing machine and X-ray diffraction. Meanwhile, the membranes pervaporation performance already discussed in our previous paper [20]

\section{MATERIALS AND METHODS}

\subsection{Materials}

The commercial grade of cellulose acetate (Sigma Aldrich, USA) with acetyl content of 39-41\%wtand Mw 30,000 was used as thematrix polymer membrane. Lampung natural zeolite (LNZ) (200 mesh) which purchased from CV. Minatama, Lampung,Indonesia was used as a filler. Acetone (J.T baker, USA) was used as solvent to dissolve cellulose acetate.

\subsection{Fabrication of Hybrid Membranes}

The hybride membranes were prepared following the procedure as published in [20]. CA was dissolved in 100 $\mathrm{ml}$ of acetone and stirred until homegeneous. Thereafter, a calculated amounts of LNZ were added into CA solutions to making the various ratios of $\mathrm{CA} / \mathrm{LNZ}$ : 30 $\% \mathrm{wt} / \mathrm{v}: 0 \% / \mathrm{w}-\mathrm{CA} ; 30 \% \mathrm{wt} / \mathrm{v}: 5 \% / \mathrm{wt}-\mathrm{CA} ; 30 \% \mathrm{wt} / \mathrm{v}$ : 10\%/w-CA: 30\%wt/v: 20\%/wt-CA; 20\%wt /v: 20\%/wt$\mathrm{CA}$. The resulting of $\mathrm{CA} / \mathrm{LNZ}$ solutions in various ratios were stirred for $24 \mathrm{~h}$, and it were set aside for 2 hours to remove the air bubbles in the mixtures.The casting solutions were casted on a glass plate and placed in the air for 20 seconds to evaporate all the solvent. The cast films were subsequently immersed in the ice water for 20 min to complete the phase separation process. Further, the membranes were heat-treated in hot distilled water $\left(80^{\circ} \mathrm{C}\right)$ to separate the membranes from the glass surface. Finally, the hybrid membranes were placed in an oven at $60{ }^{\circ} \mathrm{C}$ for 2 hours. The series of the fabrication of membrane experiments are shown in Figure 1. 


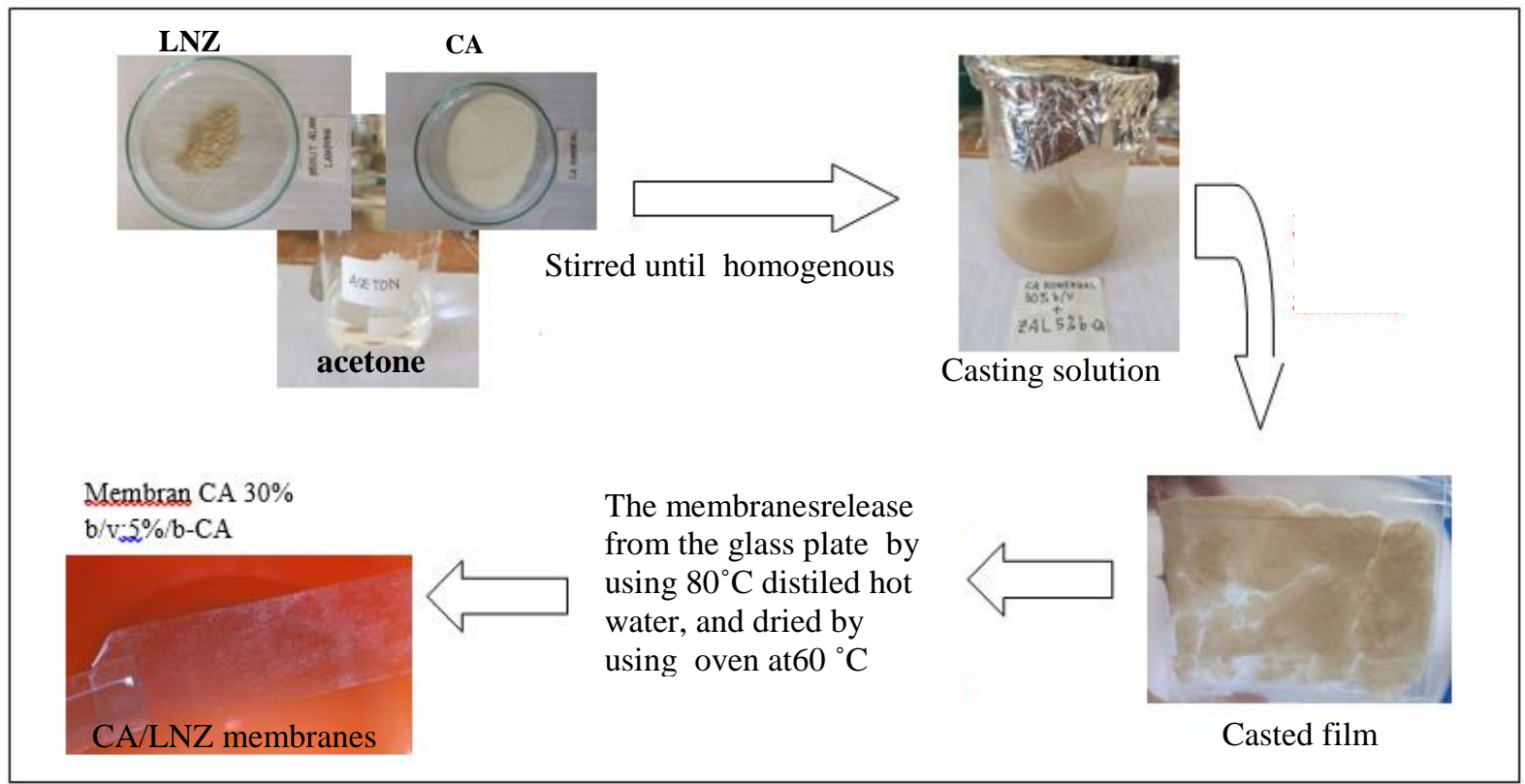

Figure 1 Schematic procedure of fabrication of pure and hybrid membranes

\subsection{Membrane Characterization}

\subsubsection{Fourier Transform Infra-Red (FTIR)}

The Fourier-transform infrared spectroscopy (FT-IR) spectra of the samples were recorded in the 400-4,000 $\mathrm{cm}^{-1}$ range using 100 Perkin Elmer, MID IR spectrometer.

\subsubsection{X-ray Diffraction (XRD)}

XRD analysis was carried out by using XRD instrument PAN analytical $X^{\prime}$ pert ${ }^{3}$ pro. The analysis used $\mathrm{Cu} \mathrm{k- \alpha}$ radiation $(\mathrm{X}=1,54 .[\dot{\mathrm{A}}])$ monochromatic, with tube voltage $40 \mathrm{kv}$ and $30 \mathrm{~mA}$ tube current. The Diffraction pattern is measured at range $2 \Theta 0-100^{\circ}$.

\subsubsection{Mechanical Stability}

The analysis of mechanical strength of the membrane $\mathrm{CA}$ and CA/LNZ were carried out at room temperature by using a Universal Testing Machine (UTM) Instron. The membrane was cut to a length of $95 \mathrm{~mm}$ and a width of $20 \mathrm{~mm}$. The sample then clamped with two aluminium clamps. One clamp is connected to the base of the lowest of the UTM and another brace in connecting with the force sensor to determine the amount of force exerted. The equation for tensile strength and percentage of elongation are shown in the Equation (1 and 2). The schematic of mechanical stability test are shown in Figure 2.

F

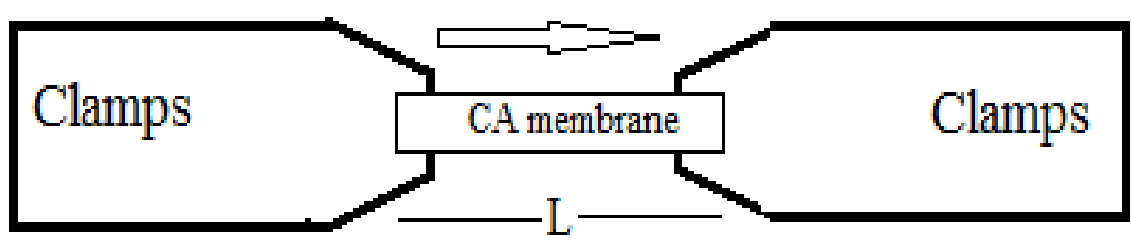

Figure 2 The schematic of mechanical stability test 


$$
\frac{F}{A}^{\sigma}=
$$

$$
\% \varepsilon=
$$

$\frac{\Delta L}{P} \times 100 \%$

Where :

$\begin{array}{lllr}\underset{(\mathrm{Mpa})}{\sigma}= & \text { Tensile } & \text { Strength } \\ \mathrm{F}= & \text { load } & \text { at } & \text { break } \\ (\mathrm{KgF}) & & & \end{array}$

\footnotetext{
A $=$ cross-sectional area $\left(\mathrm{mm}^{2}\right)$

$\varepsilon \quad=$ Elongation $(\%)$

$\mathrm{P} \quad=$ initial length $(\mathrm{mm})$

$\Delta \mathrm{L} \quad=$ length differences $(\mathrm{mm})$
}

\subsubsection{Scanning Electron Microscopy (SEM)}

The top surface and cross sectional morphology of the $\mathrm{CA}$ and $\mathrm{CA} / \mathrm{LNZ}$ membranes in the different ratios were studied using scanning electron microscopy (ZEISS EVO
MA 10). All of the sample specimens were coated with a thin layer of gold to prevent charging

\subsubsection{DTA/TGA}

Thermal stability analysis of the membrane samples were performed by using EXSTAR TG/DTA7300 analyzer at condition i.e: (1) heating rate $20{ }^{\circ} \mathrm{C} / \mathrm{min}$, (2) range of temperature programs were $30-600{ }^{\circ} \mathrm{C}$ under oxygen-free condition (nitrogen atmosphere), and (3) Nitrogen flow was $20 \mathrm{ml} / \mathrm{min}$ in order to remove all corrosive gas involved in the degradation.

\section{RESULTS AND DISCUSSION}

\subsection{Fourier Transform Infra-Red (FTIR)}

The FTIR spectra analysis results of membranesin varied compositions of CA/LNZ were shown on Figure 3. All of the peaks obtained from FTIR instrument has been confirmed by some of the literature data $[1,8,21]$. In the spectrum of pure CA membrane, the peaklocated at $3453 \mathrm{~cm}^{-1}$ is associated to the stretching vibration of hydroxyl group $(-\mathrm{OH})$. The peak of the $\mathrm{C}=\mathrm{O}$ bond appeared around wave number about $1640 \mathrm{~cm}^{-1}$ and 1736 $\mathrm{cm}^{-1}$ assigned to the presence of an acetyl group. The spectraaroundthe wave number $2926 \mathrm{~cm}^{-1}$ and $1371 \mathrm{~cm}$ ${ }^{1}$ shows the presence of $\mathrm{C}-\mathrm{H}$ bond. Peak observed at wave number $1225 \mathrm{~cm}^{-1}$ asigned the $\mathrm{C}-\mathrm{O}-\mathrm{C}$ which also described the presence of an acetyl group.

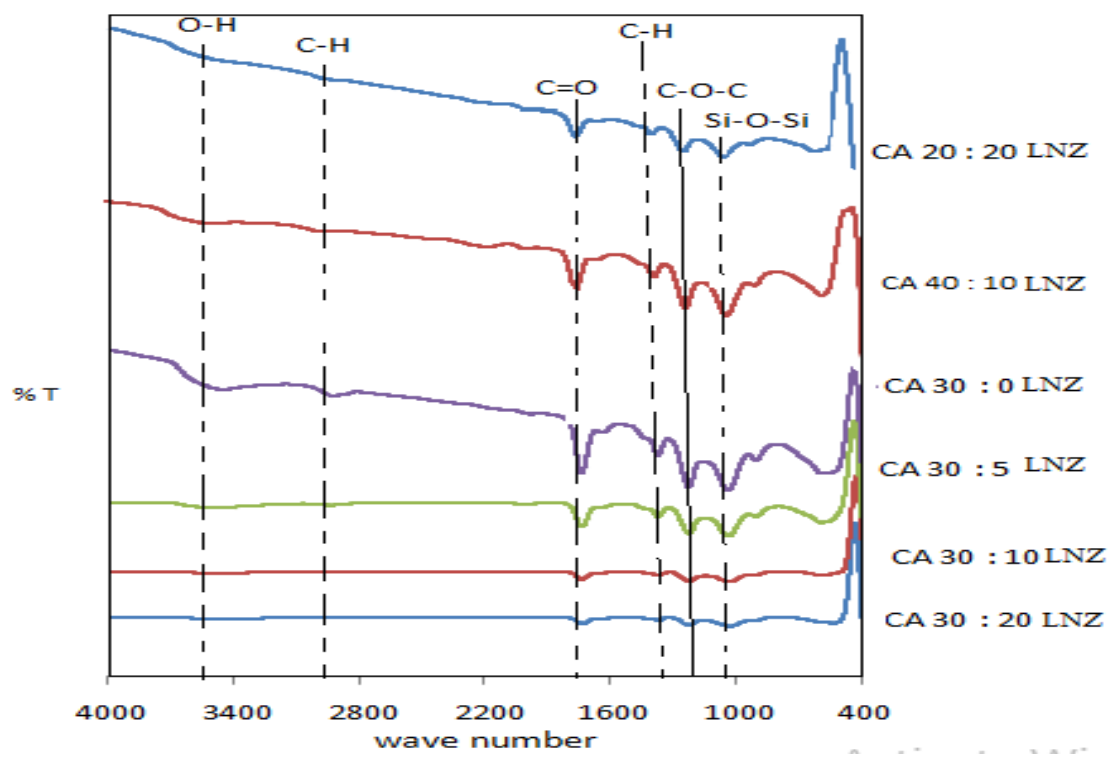

Figure 3 FTIR Spectra data of membrane in varied ratio of CA and LNZ 
ram

In the spectrum of $\mathrm{CA} / \mathrm{LNZ}$ membrane, it shows that the addition of LNZ into the CA matrix affects on shifting of $-\mathrm{OH}, \mathrm{C}=\mathrm{O}$ and $\mathrm{C}-\mathrm{H}$ bond. The intensity of the band at around $3453 \mathrm{~cm}^{-1}, 1640 \mathrm{~cm}^{-1}$ and, $1225 \mathrm{~cm}^{-1}$ assigned in the bending vibration due to the presence of silica $\mathrm{Si}-\mathrm{O}$ $\mathrm{Si}$ from LNZ. This result shows that the hydrophilic nature of the membrane increases. The stretching vibrations also occurs on the cluster $\mathrm{C}-\mathrm{H}, \mathrm{C}=\mathrm{O}$ and $\mathrm{C}$ $\mathrm{O}-\mathrm{C}$ which is caused by the interaction between $\mathrm{CA}$ and LNZ This results confirmed that there are exist the interaction between CA and LNZ. This results confirmed that the membrane has been homogenized.

\subsection{Mechanical Stability Analysis.}

The mechanical stability of the membraneswere evaluated its tensile properties, i.e., tensile strength and the elongation at break. It is observed that the filled membranes show much lower tensile strength than the pure of CA membrane. In spite of elongation properties, the filled membranes show decrease marginally with an increase of the filler.

The membranes which have good mechanical strength must have thevalue of percentage elongation and balanced tensile strength. A very high tensile strength without much elongation causes the rigidityof the membranes while the high elongation makes the membrane soft [2]. The results of mechanical stability of membranes test shown that the membrane in ratio of CA/LNZ 20: 20, 20:10 and 20:30indicate the good balance of tensile strength and percentage of elongation. This results explained that the presence of LNZ as a filler into matrix membrane were able to improve the mechanical performance of CA membrane. Thus, the modified membranes can be suitable used for pervaporation process without any mechanical failure.

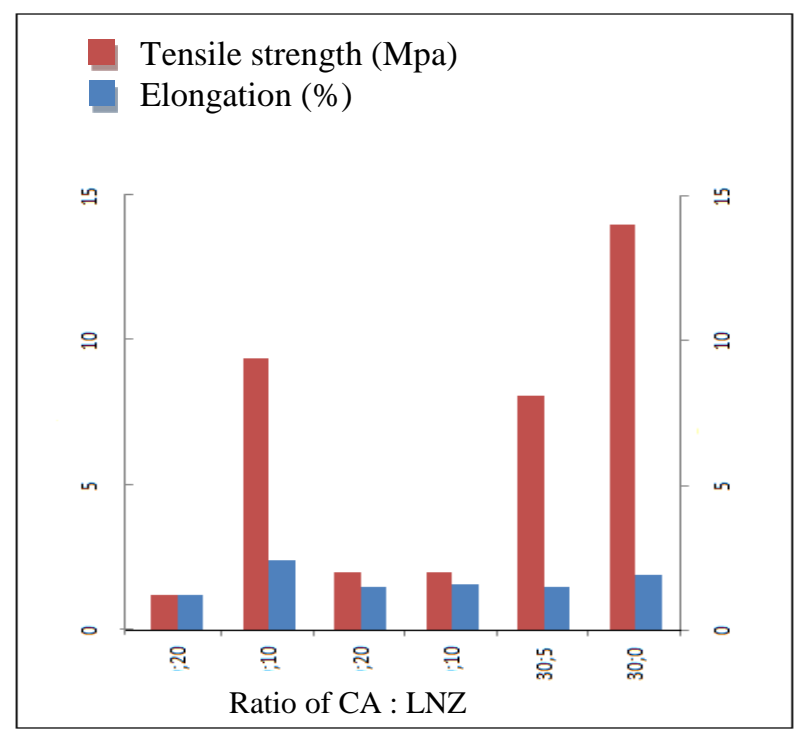

Figure 4 Results of Mechanical Stability Analysis (tensile strength vs elongation)

\subsection{X-Ray diffraction (XRD)}

The XRD analysis showed the characteristics of the membrane structure, properties of amorphous or crystalalyne of pure CA and CA/LNZ membranes in varied ratios. The diffraction patterns of pure $C A$, CA/LNZ with different LNZ concentrations are shown in Fig. 6. It can be seen that the XRD pattern of pure CA shows like all other natural polymers was partial crystalline nature [7]. The XRD patterns of CA/LNZ with low LNZ concentrations in presence were similar patterns with pure CA membrane. However, when high concentration of LNZ are added to CA matrix membranes, the intensity of XRD spectra $2 \Theta$ were increased. It was observed that the characteristic peak of CA/LNZ in ratio of 30:20 and 20:20 the LNZ particles located at $23.07^{\circ}$. This results was indicatedthat the addition of LNZ into CA matrix membrane was influenced the crystallinity of membrane and improved the mechanical properties of the membrane due to interaction between CA and LNZ. 


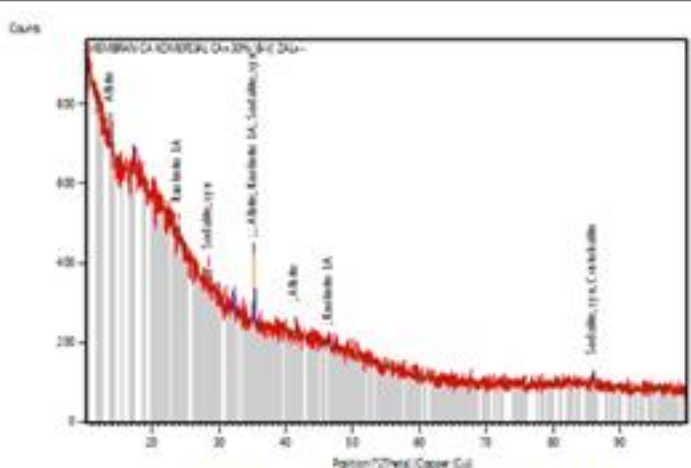

(a) $30 \% \mathrm{~b} / \mathrm{v}$ CA: 0\%/b-CA ZAL

ton

(a). $30 \% \mathrm{~b} / \mathrm{v}$ CA : $0 \% / \mathrm{b}-\mathrm{CA}$ LNZ

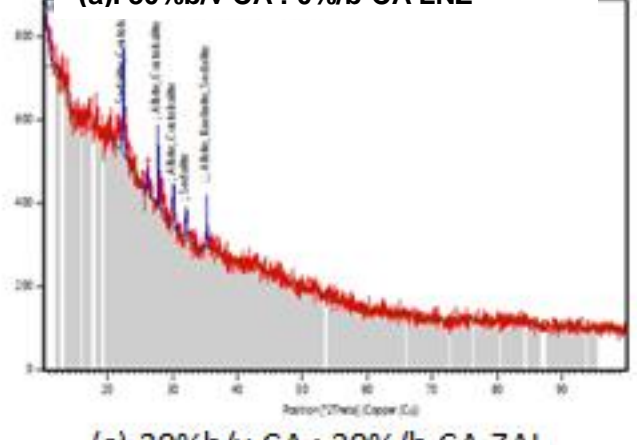

(c). $30 \% \mathrm{~b} / \mathrm{v}$ CA : $20 \% / \mathrm{b}-\mathrm{CA}$ LNZ

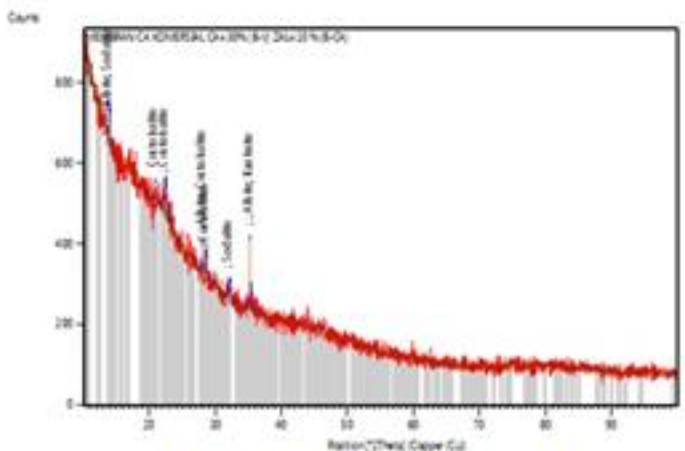

(b) $30 \% \mathrm{~b} / \mathrm{v}$ CA: $10 \% / \mathrm{b}-\mathrm{CA}$ ZAL

(b). $30 \%$ b/v CA : 10\%/b-CA LNZ

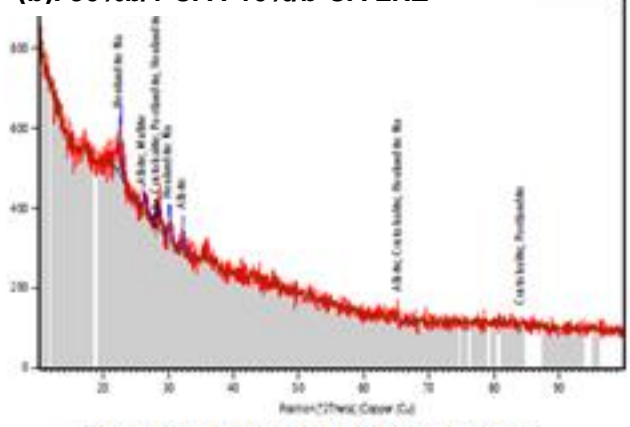

(d) $20 \% \mathrm{~b} / \mathrm{v}$ CA: $20 \% / \mathrm{b}-\mathrm{CA}$ ZAL

(d). $20 \% \mathrm{~b} / \mathrm{v}$ CA : $20 \% / \mathrm{b}-\mathrm{CA}$ LNZ

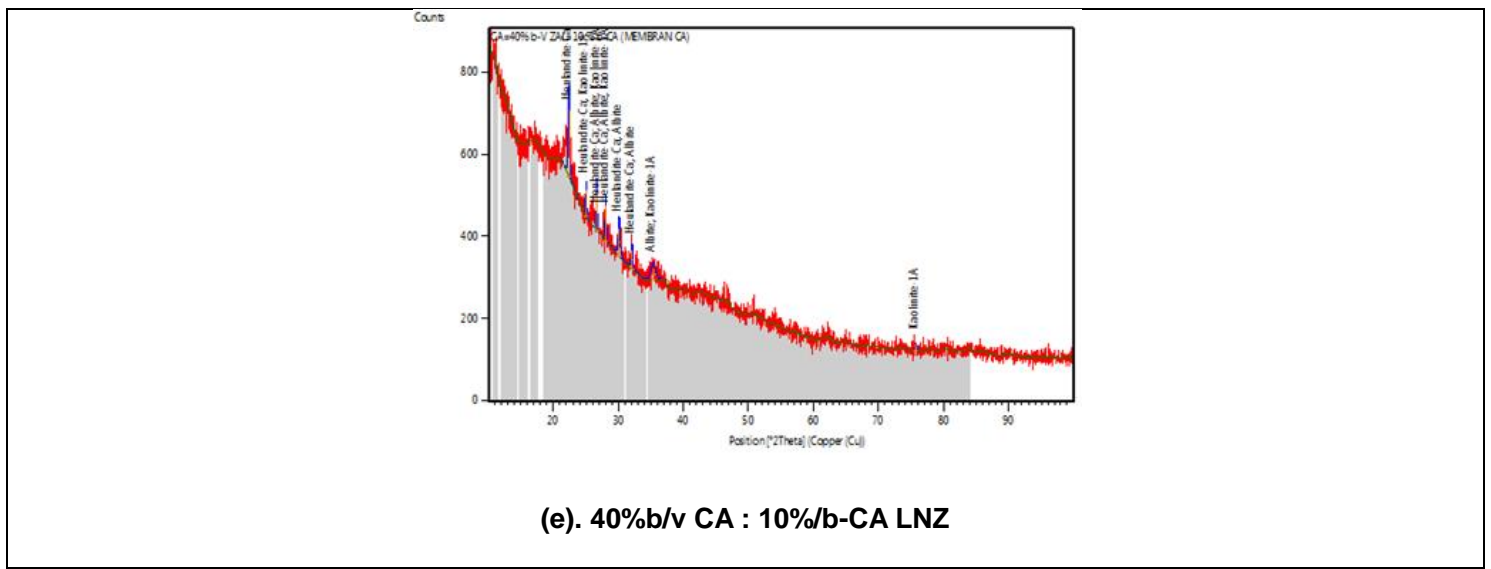

Figure 5 X-ray diffraction patterns of pure CA, and CA/LNZ membranes in varied ratio

\subsection{Scanning electron microscopy (SEM)}

The scanning electron micrograph (SEM) characterizations of $\mathrm{CA}$ pure and hybrid $\mathrm{CA} / \mathrm{LNZ}$ membranes were shown in Figure 5. The morphologies of pure CA and CA filled with LNZ are shown in Fig. 5(a) indicates the smooth surface of pure CAmembrane, and Fig. 5(b) shows that the top surface of hybrid membranes. On the surface of pure membrane, it was observed that a dense featureless morphology. Dissimilar 
with the pure of CA membrane, there were many protrusions on the surface of the hybrid $\mathrm{C} / \mathrm{LNZ}$ membrane, which consisted of particles of LNZ or their aggregates. The LNZ filled into the matrix Ca membrane was not change the properties of denser membrane, it is evidenced by no spongy holes in the cross-section (Fig. 5(c) and (d)).

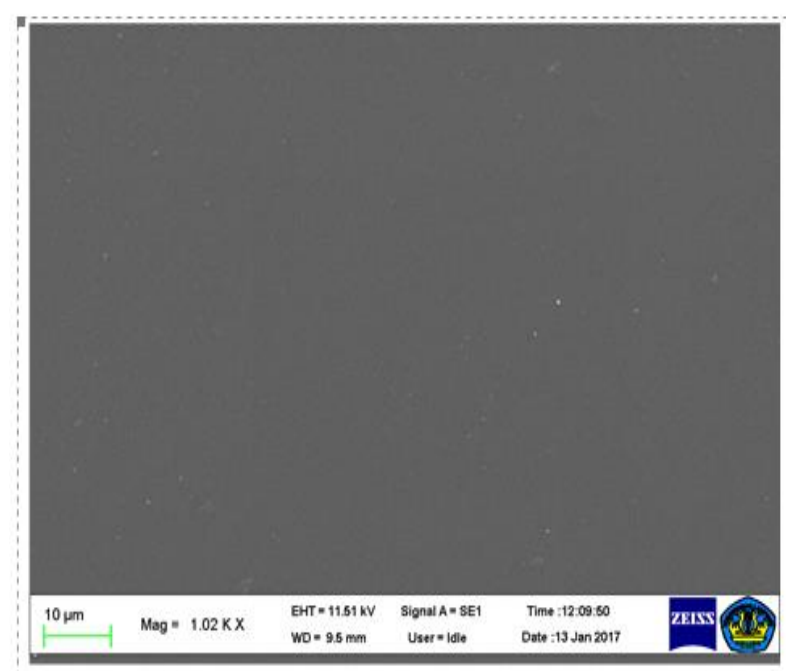

(a)

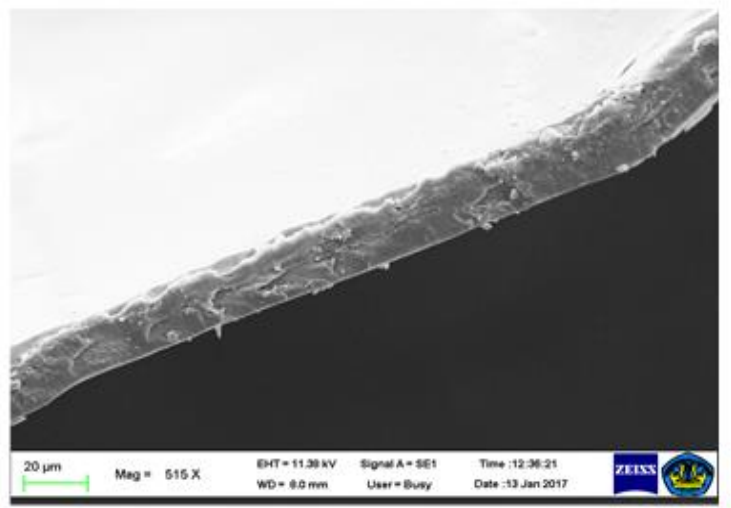

(c)

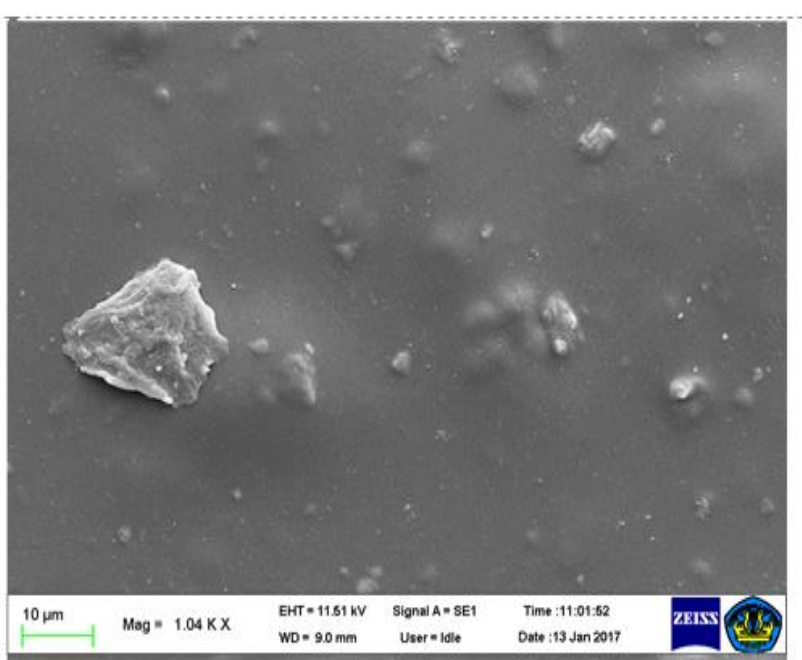

(b)

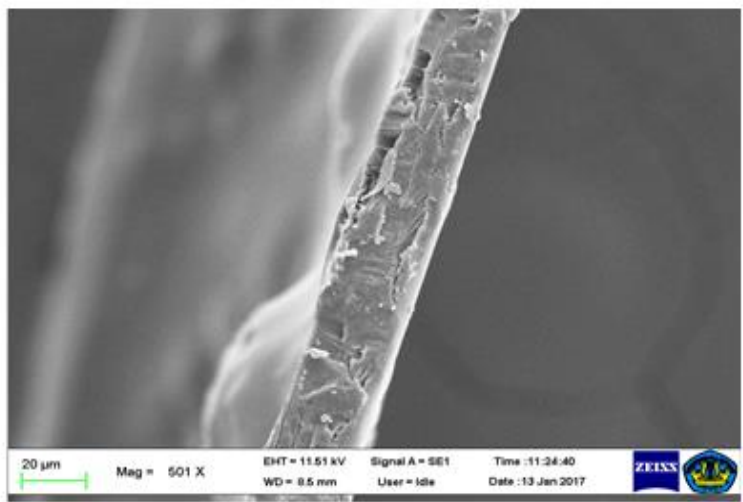

(d)

Figure 6 Morphology of pure CA membrane and CA/LNZ Membrane: (a) surface of pure CA membrane; (c) surface of CA membrane filled with LNZ (30:20); (c) cross-section of pure CA membrane; (d) cross-section of membrane filled with filled with LNZ (30:20).

The addition of LNZ particles into the CA matrix solution resulted in a larger viscosity than of the CA solution. Thus, the viscosity of mixture would increase with the increase of mass content of LNZ, which was resulting an increase of the dehydration performance of ethanol on the pervaporation process [20].

\subsection{Thermal Analysis (DTA/TGA)}

The thermal stabilities and degradation behavior of pure membrane $\mathrm{CA}$ and $\mathrm{CA} / \mathrm{LNZ}$ were evaluated by
TGA/DTA analysis instrument under nitrogen atmosphere. The TGA/DTAanalysis was restricted to samples with a variation of $30 \% \mathrm{w} / \mathrm{v}$ : $0 \% \mathrm{w}-\mathrm{CA}$ and $30 \%$ w/v: $20 \%$ w-CA. Figure 7 and 8 shows that the degradation of all the CA and hybrid membranes occurs in three stages. The first stage, from the room temperature 30-160 ${ }^{\circ} \mathrm{C}$, represents the evaporation of water or volatile matter. The second stage, at $240-320^{\circ} \mathrm{C}$, represents the main thermal degradation of the cellulose acetate chains. The third step, up to $320-400{ }^{\circ} \mathrm{C}$, shows degradation products into ash. At the temperature of around $366^{\circ} \mathrm{C}$ 
membrane completely degraded. In the other hand, membranes CA/LNZ degradation firts stage occurs at the temperature of $30-110^{\circ} \mathrm{C}$ represent the evaporation of water or volatile content in the membrane evaporation $\mathrm{CA}$. The second stage, at the temperature of $240^{-} 350^{\circ} \mathrm{C}$ decomposition of cellulose acetate occured, and the last stage aroundthe temperature of $350^{\circ} \mathrm{C}$ to $420^{\circ} \mathrm{C}$ the membrane degraded into ash. At the temperature around of $381^{\circ} \mathrm{C}$ membrane already started to decompose. Based on these results, it can be concluded that the addition of LNZ able to improve the thermal stability and retard the thermal degradation of hybrid membranes; this result was similar with previous reports $[1,7,17]$.

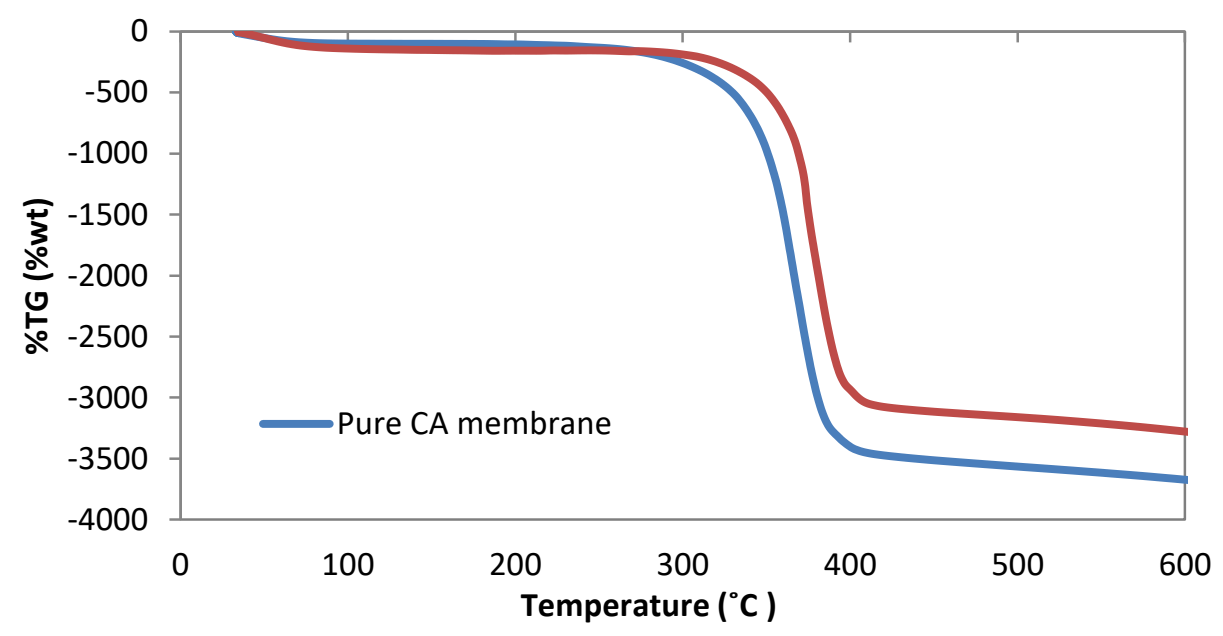

Figure 7 Comparisson result ofthermogram of membrane CA and CA/LNZ

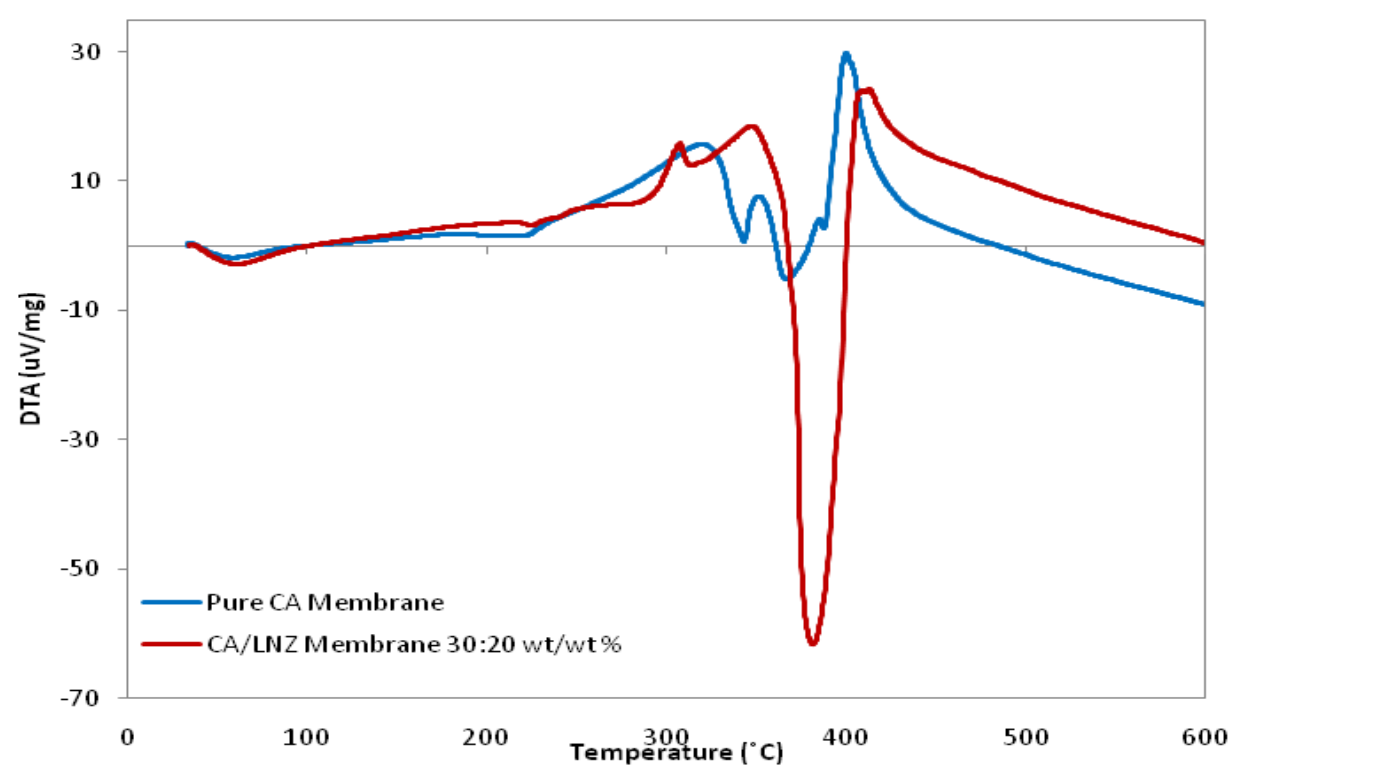

Figure 8 The DTA analysis result of Pure CA and hybrid CA/LNZ membranes 


\section{CONCLUSIONS}

CA/LNZ hybrid membranes were prepared via phase inversion by dispersing the Lampung natural zeolite particle into the CA casting solution. The addition of LNZ into the CA casting solution improved the membrane properties. The conclusions can be listed as follows:

1. It was possible to produce membranes of cellulose acetate hybrid membrane by using natural zeolite. The addition of natural zeolite (LNZ) improve the performance better than pure CA membrane and it is found to be inexpensive and easy to prepare.

2. SEM images show that the LNZ filled into the matrix Ca membrane was not change the properties of denser membrane.

3. The results from mechanical stability test, XRD, and TGA/DTA analysis shows that by increasing the addition of LNZ particles in the casting solution influenced the crystallinity of membrane and improved the mechanical and thermal stability properties of the membrane due to interaction between CA and LNZ.

4. This study may provide useful information to further develop some inexpensive pervaporation membrane for used in separation and dehydration of ethanolwater in industrial.

\section{ACKNOWLEDGMENT}

The authors gratefully acknowledge the financial support of the Directorate General of Higher Education, National Ministry of Republic Indonesia and University of Lampung or research grant of "Hibah Fundamental Dikti 2016" and "Hibah Professor 2017". This study was successfully done by the facilities support of Integrated Laboratory and Innovation Technology Center University of Lampung.

\section{REFERENCES}

[1] Ma X., Hu C., Guo R., Fang X., Wu H., Jiang Z., Preparation of cellulose acetate/zeolite composite fiber and its adsorption behavior for heavy metal ions in aqueous solution, vol. 209, Chemical Engineering Journal, 2012, pp. 325-333

[2] Samanta H.S., Ray S.K., Separation of ethanol from water by pervaporation using mixed

matrix copolymer membranes. Separation and Purification Technology, 2014.

DOI: $\quad$ http://dx.doi.org/10.1016/j.seppur. 2015.03.006
[3] Le N.L., and Suzana P.N., Materials and membrane technologies for water and energy sustainability, vol. 7, Sustainable Materials and Technologies, 2016, pp. 1-28.

[4] Arthanareeswaran G., Sriyamuna D., Raajenthiren M., Effect of silica particles on cellulose acetate blend ultrafiltration membrans: Part I, vol. 64, Separation and Purification Technology, 2008, pp. 38-47.

[5] Ji F., Li C., Tang B., Xu J., Lu G., Liu P., Preparation of cellulose acetate/zeolite composite fiber and its adsorption behavior for heavy metal ions in aqueous solution, vol. 209, Chemical Engineering Journal, 2012, pp. 325-333.

[6] Guleca H.A., Topaclib A., Topaclib C., Albayraka N., Mutluc M., Modification of cellulose acetate membrane via low-pressure plasma polymerization for sugar separation applications: Part I, vol. 350, Membrane development and characterization Journal of Membrane Science, 2010, pp. 310-321.

[7] Kamal H., Abd-Elrahim F.M., Lotfy S., Characterization and some properties of cellulose acetate-co-polyethylenen oxide blends prepared by the use of gamma irradiation, vol. 7, Journal of Radiation Research and Applied, 2014, pp. 146153.

[8] Minhas F.T., Farrukh S., Hussain A., Mujahid M., Comparison of silica and novel functionalized silica-based cellulose acetate hybrid membrans in gas permeation study, vol. 22, Journal Polymer Res., 2015, pp. 2-13.

[9] Abedini R., Mousavi S.M., Aminzadeh R., A novel cellulose acetate (CA) membrane using TiO2 nanoparticles: Preparation, characterization and permeation study, vol. 277, Desalination, 2011, pp. 40-45.

[10] Saljoughi E., Sadrzadeh M., Mohammadi T., Effect of preparation variables on morphology and pure water permeation flux through asymmetric cellulose acetate membranes, vol. 326, Journal of Membrane Science, 2009, pp. 627-634.

[11] Chapman P.D., Oliveirab T., Livingstona A.G., Li K., Membranes for the dehydration of solvents by pervaporation, vol. 318, Journal of Membrane Science, 2008, pp. 5-37.

[12] Kanse, N.G., and Dawande S. D., A Review of pervaporation membrane system for the 
separation of ethanol/water (azeotropic mixture) International Journal Engineering Scince \& Research Techology, 2015,. ISSN: 22779655(http: // www.ijesrt.com)

[13] Kanagaraj P., Neelakandan S., Nagendran A., Preparation, Characterization and Performance of Cellulose Acetate Ultra filtration Membrane Modified by Charged Surface Modifying Macro molecule, vol. 31(6), Korean Journal of Chemical Engineering, 2014, pp. 1057-1064.

[14] Arthanareeswaran G., Thanikaivelan P., Srinivasan K., Mohan D., Rajendran M., Synthesis, Characterization and Thermal Studies on Cellulose Acetate Membranes with Additive, vol. 40, European Polymer Journal, 2004, pp. 2153-2159.

[15] Wang Y., Yang L., Luo G., Dai Y., Preparation of Cellulose Acetate Membrane Filled with Metal Oxide Particles for the Pervaporation Separation of Methanol/Methyl Tert-Butyl Ether Mixtures, vol. 146, Chemical Engineering Journal, 2009, pp. 6-10.

[16] Dogan H., and Hilmioglu N.D., Chitosan coated zeolite filled regenerated cellulose membrane for dehydration of ethylene glycol/water mixtures by pervaporation, vol. 258 , Desalination, 2010, pp. 120-127.
[17] Abedini R., Mousavi S.M., Aminzadeh R., A novel cellulose acetate (CA) membrane using $\mathrm{TiO}_{2}$ nanoparticles: Preparation, characterization and permeation study, vol. 277 , Desalination, 2011, pp. 40-45.

[18] Ling L. K., Ghazali M., Nawawi M., Sadikin A.Z., Pervaporation of Ethanol-Water Mixture Using PVA Zeolite-Clay, vol. 49(F), Membranes Journal Teknologi UniversitiTeknologi Malaysia, 2008., pp. 167-177.

[19] Ji F., Li C., Bo T., Xu J., Lu G., Liu P., Preparation of cellulose acetate/zeolite composite fiber and its adsorption behavior for heavy metal ions in aqueous solution, vol. 209, Chemical Engineering Journal, 2012, pp. 325-333.

[20] Iryani D.A.,Wulandari N.F.,Cindra Dewi A.W., Ginting S., Ernawati E., Hasanudin, U., Lampung natural zeolite filled cellulose acetate membrane for pervaporation of ethanol-water mixtures, vol 141(012013), IOP Conference Series: Earth and Environmental Series, 2018, pp. 1-8. doi :10.1088/1755-1315/141/1/012013

[21] Kanagaraj P., Neelakan dan S., Nagendran A., Preparation, characterization and performance of cellulose acetate ultrafiltration membranes modified by charged surface modifying macromolecule, vol. 31(6), Korean J. Chem. Eng, 2014, pp. 1057-1064. 